\title{
Formation of vacancy-type defects in titanium nickelide
}

\author{
Anatolii Baturin ${ }^{1,2, a}$, Aleksander Lotkov ${ }^{1,3}$, Victor Grishkov ${ }^{1}$ and Andrei Lider ${ }^{3}$ \\ ${ }^{1}$ Institute of Strength Physics and Materials Science, SB RAS, Russia \\ ${ }^{2}$ Tomsk Polytechnic University, Russia \\ ${ }^{3}$ Tomsk State University, Russia
}

\begin{abstract}
In this report we briefly review the current state-of-the-art and challenges in determining point defect properties from first-principles calculations as well as from experimental measurements in titanium nickelid. Based on the vacancy formation energy and the activation energy for vacancy migration in $\mathrm{TiNi}$, vacancy mediated diffusion mechanism was examined. The influence of vacancies and antisite defects on the TiNi structural phase transition has been described.
\end{abstract}

\section{Introducing}

Investigating diffusion processes in titanium nickelid alloys sharpened several issues on types and characteristic features of point defects. In the publication of Bastin and Riek [1] it was established that the chemical diffusion coefficient in TiNi is determined by $\mathrm{Ni}$ diffusion, and the activation energy for diffusion is too small $(\sim 1.4 \mathrm{eV})$ compared to other B2 intermetallic compounds. Investigating $\mathrm{Ni}$ diffusion in relation to pressure [2] showed that activation volume of diffusion $\mathrm{Ni}$ in TiNi within experimental error is equals zero. This could imply that diffusion mechanism is interstitial mediated or that there are structural vacancies in the intermetallic compound. Diffusion mechanism in TiNi is a particular case to explain the common diffusion mechanism in B2 intermetallic compounds. As discussion of the diffusion mechanism in B2 intermetallic, causes disputes [3-5], research of point defects in TiNi is relevant. Besides, some authors [6-9] state that point defects configuration of a B2 phase can play an important role in nucleation and growth processes of martensitic phase.

\section{Vacancy formation energy in titanium nickelid}

In $\mathrm{AB}$ compounds with $\mathrm{B} 2$ structure interatomic potentials of identical atoms $\mathrm{AA}$ and $\mathrm{BB}$ have distinct dependency on the distance between identical atoms in given coordination sphere; further, interatomic potentials of these identical atoms also have a different potential well [9]. This results in the fact that the vacancy formation energy $\left(E_{v}\right)$ on the different atomic sublattices is non-identical, which, in its turn, could be revealed in

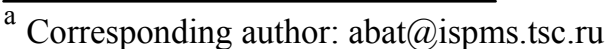

some B2 compounds by the positron annihilation spectroscopy (PAS) method [10].

Presently, investigations in measurement the vacancy formation energy in a series of intermetallic compounds $\mathrm{Fe}_{3} \mathrm{Al}$ [11], TiAl [12], $\mathrm{Fe}_{3} \mathrm{Si}$ [13], $\mathrm{Ni}_{3} \mathrm{Al}$ [14] have been conducted via positron annihilation spectroscopy method. There are also investigations in determining $\mathrm{E}_{\mathrm{v}}$ in $\mathrm{B} 2$ intermetallics $[15,16]$. For example, in [15] two alloys $\mathrm{Fe}_{61} \mathrm{Al}_{39}$ and $\mathrm{Fe}_{63} \mathrm{Al}_{37}$ in $\mathrm{B} 2$ structure were studied by positron annihilation lifetime spectroscopy (temperature dependency of average positron lifetime was investigated).

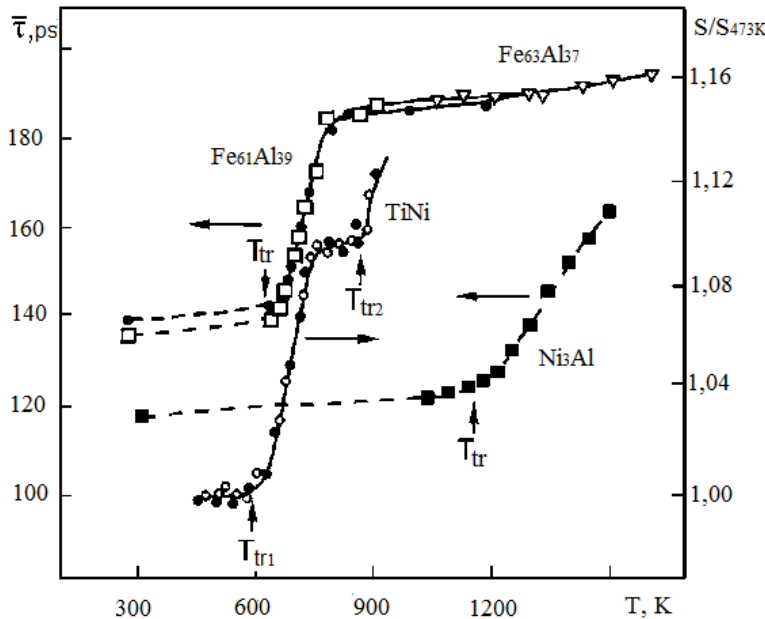

Figure 1. Dependency of average positron lifetime and normalized S-parameter from temperature indicating vacancy formation at $\mathrm{T}>\mathrm{T}_{\text {tr }}$, in alloys $\mathrm{Fe}_{63} \mathrm{Al}_{37}(\mathrm{)}), \mathrm{Fe}_{61} \mathrm{Al}_{39}(\bullet)$ [15]; $\mathrm{Ti}_{50} \mathrm{Ni}_{50}\left(\bullet\right.$ - heating, o - cooling) [16] in B2-phases; $\mathrm{Ni}_{3} \mathrm{Al}\left(\mathrm{LI}_{2}\right)$ (-) $[14]$.

In the reference well-annealed state average positron lifetime corresponds to a delocalized positron state, i.e. the vacancy concentration in a sample lower than the PAS method threshold limit. Further, when heating the 
sample within temperature range $600 \mathrm{~K}<\mathrm{T}<740 \mathrm{~K}$, starting with a temperature $T_{\text {tr }}\left(T_{t r}-\right.$ the temperature at which vacancies are first detectable by positron [17]), an average positron lifetime exponential increase is observed with subsequent saturation, which, in its turn, indicates saturated positron trapping of thermal vacancies (figure 1). According to theoretical estimates [10], if $E_{v}$ on $\mathrm{Fe}$ sublattice atoms is several times less than $\mathrm{E}_{\mathrm{v}}$ on $\mathrm{Al}$ sublattice, then positron trapping occurs only on $\mathrm{Fe}$ vacancies. The vacancy formation energy value for these alloys is also low $(\sim 1 \mathrm{eV})$ compared to both pure metals and alloys with close-packed structure, for example, in $\mathrm{Ni}_{3} \mathrm{Al}\left(\mathrm{L}_{2}\right) \mathrm{E}_{\mathrm{v}}=1.8 \mathrm{eV}$ [14].

Investigation of vacancies in titanium nickelid was of special interest [16]. Positron lifetime spectra shows [18] that positron annihilation in TiNi at temperatures lower than $500 \mathrm{~K}$ is a result of delocalized state, i.e. positron trapping by structural defects is not observed. In [16], $\mathrm{E}_{\mathrm{v}}$ in TiNi was determined by PAS according to the changing S-parameter the one-dimensional angular correlation of annihilation radiation (1D-ACAR) [19] at heating and cooling stages. S-parameter was defined as ratio of low-momentum area of $1 \mathrm{D}$-ACAR to the total area. The investigation was conducted for B2 phase of TiNi in the temperature interval of $480 \div 900 \mathrm{~K}$.

The curve $\mathrm{S}(\mathrm{T})$ for $\mathrm{TiNi}$ alloys has been depicted in figure 1, where $\mathrm{S}(\mathrm{T})$ has non-monotonic dependence and four temperature intervals can be extracted on this curve. In interval I $(473 \mathrm{~K} \div 600 \mathrm{~K}), \mathrm{S}(\mathrm{T})$ has a very weak temperature dependence reflecting the thermal expansion of a lattice [20]. In interval II $(600 \mathrm{~K} \div 730 \mathrm{~K}), \mathrm{S}(\mathrm{T})$ increases sharply in accordance with exponential law and terminates in a plateau (interval III). S(T) invertibility change in the "heating-cooling" cycle shows that for each of the temperature reached an equilibrium state.

Such $\mathrm{S}(\mathrm{T})$ behavior in the temperature interval $600 \mathrm{~K} \div 730 \mathrm{~K}$ is typical for positron trapping by thermal vacancies. At $\mathrm{T}>830 \mathrm{~K}$ another the increase stage of $\mathrm{S}(\mathrm{T})$ is observed, resulting of the formation of new positron trapping centers. Analogous behavior of $\mathrm{S}(\mathrm{T})$ has been previously observed in B2 an ordered CuZn alloy [21], what, in its turn, implies that in $\mathrm{CuZn}$ and TiNi, at increasing temperature, thermal vacancy concentration changes by the same scenario. As the positron trapping at $\mathrm{T}>830 \mathrm{~K}$ has not been adequately examined in a wide temperature range [16], to determine vacancy formation energy empirical correlation of temperature $T_{t r}$ and $E_{V}$ [22] has been used:

$$
E_{v}=1.29 \cdot 10^{-3} T_{t r}(\mathrm{eV})
$$

Temperatures $\mathrm{T}_{\text {tr }}$ for $\mathrm{B} 2$ phase TiNi has the values: $\mathrm{T}_{\text {tr } 1}=(605 \pm 10) \mathrm{K}$ and $\mathrm{T}_{\mathrm{tr} 2}=(750 \pm 20) \mathrm{K}$, which, in its turn, determine the following values: $\mathrm{E}_{\mathrm{v} 1}=(0.78 \pm 0.02) \mathrm{eV}$ and $\mathrm{E}_{\mathrm{v} 2}=(0.97 \pm 0.05) \mathrm{eV}$.

These two $E_{v}$ values are governed by the characteristic features of interatomic interaction in B2 structure TiNi. Interatomic force constant, calculated in [23], shows that in B2- phase of TiNi, Ni-Ni interaction is significantly weaker than Ti-Ti interaction. Based on this fact, lower value $\mathrm{E}_{\mathrm{v} 1}$ could be assigned to energy vacancy formation on sublattice of $\mathrm{Ni}$ atoms, and $\underline{\mathrm{E}}_{\mathrm{v} 2}$ - on sublattice of Ti atoms

Recently, accordingly to [24], independent verification of results [16] was obtained. Based on positron monoenergy beams, the temperature dependence of the $\mathrm{S}$ parameter of the Doppler-broadening was measured in situ [24]. Compared to [16], the measurement of $\mathrm{S}$ parameter was conducted under conditions of cooling from high temperatures with low constant cooling rate and not-too-high statistical accuracy. Presumably, it is this fact that the authors [24] could not observe the positron trapping of two vacancy types. However, observed value $\mathrm{E}_{\mathrm{v}}=0.77 \pm 0.08 \mathrm{eV}$ perfectly coincided with the observed value $0,78 \mathrm{eV}$ [16] for vacancy formation on $\mathrm{Ni}$ sublattice.

Theoretical estimates $\mathrm{E}_{\mathrm{v}}$ for TiNi were conducted in reference [25, 26]. In [25] based on molecular-based static method effective vacancy formation energy in B2 intermetallics $\mathrm{TiFe}$ and $\mathrm{TiNi}$ was calculated. $\mathrm{E}_{\mathrm{v}}$ for TiNi equaled $1.48 \mathrm{eV}$, which higher than the experimental values. Theoretical investigation of point defects and their interaction in TiNi [26] was conducted by the first principle of plane wave pseudopotential method, based on density functional theory (DFT). In particular, $\mathrm{E}_{\mathrm{v}}$ was calculated for high-temperature B2- and martensitic phases B19 and B19'.

Given that measuring $E_{v}$ by PAS method is impossible in martensitic phases (due to the fact that vacancy concentration in low temperature zones is lower than threshold limit of PAS method), then it is theoretical value comparable only with B2 phase. The vacancy formation energy on sublattice of Ni atoms is $\mathrm{E}_{\mathrm{v}}=1.09 \mathrm{eV}$ [26], which is within $20 \%$ coincides with the experimental data [16]. The vacancy formation energy on sublattice of $\mathrm{Ti}$ atoms is $\mathrm{E}_{\mathrm{v}}=1.74 \mathrm{eV}$ and is higher than the experimental value $0.98 \mathrm{eV}$ [16]. It has been proved that both experimental [16] and theoretical [26] data supports the different $E_{v}$ values for vacancy on sublattice of $\mathrm{Ti}$ and $\mathrm{Ni}$ atoms. The $\mathrm{E}_{\mathrm{v}}$ difference was estimated within the framework of pseudopotential method for vacancy on $\mathrm{Ti}$ and $\mathrm{Ni}$ sublattices [9]. The authors [9] obtained the value $0.16 \mathrm{eV}$ which fairly coincides with the above-mentioned experimental data- $0.19 \mathrm{eV}$. The results indicate that the favorable point defect is $\mathrm{Ni}$ vacancies in $\mathrm{B} 2$ phase TiNi alloys.

\section{Determining activation energy for vacancy migration in $\mathrm{TiNi}$}

Activation energy for vacancy migration $E_{m}$ in metallic compounds is determined by the nature of interatomic interactions, which, in its turn, defines energy barrier height for atoms jumping in vacant state. The value $E_{m}$ can be obtained by PAS method based on measurement of annealing vacancies induced by electron irradiation Measurements [27] showed that in B2 compounds the value positron lifetime in vacancies is practically identical in vacancies, induced by electron irradiation or in thermal vacancies (FeAl, NiAl) and coincide with first principles theoretical calculations. Thus, the investigation of annealing kinetics of radiation vacancies 
(isothermal or isochronic) could provide information about the activation energy for vacancy migration.

Electron irradiation it was carried out at $150 \mathrm{~K}$, i.e. in martensitic phase $\left(\mathrm{E}_{\mathrm{e}}=2,0 \mathrm{MeV}, \mathrm{F}=2 \cdot 10^{22} \mathrm{~m}^{-2}\right)$, however, isochronic annealing is studied in B2 phase (figure 2).

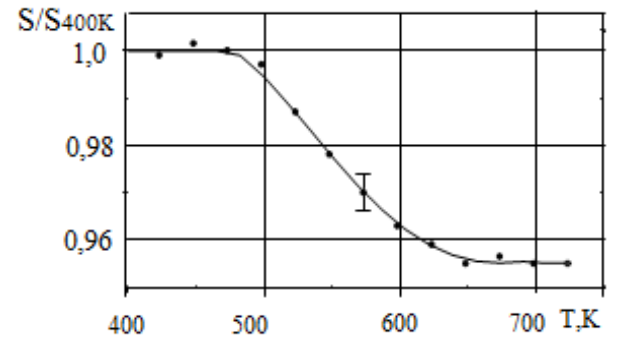

Figure 2. Changing normalized S-parameter depending on isochronic annealing temperature of $\mathrm{TiNi}$ induced electron radiation; annealing time at each temperature interval is 20 minutes.

It is obvious that changing S-parameter ranges within 473-623K, after which the annealing process is completed and $\mathrm{S}$ has the reference value of non-irradiated sample. Irradiated condition and temperature interval involving irradiation-induced defects $\left(\sim 0.33 \mathrm{~T}_{\mathrm{m}}\right)$ presumes that irradiation generates monovacancies [28]. Determination of $\mathrm{E}_{\mathrm{m}}$ was conducted in presumed monomolecular annealing kinetic with a value of $(0.7 \pm 0,1) \mathrm{eV}$. In analogous presumptions [29] $\mathrm{E}_{\mathrm{m}}$ was determined based on resistivity of quenched alloy samples $\mathrm{Ti}_{49,4} \mathrm{Ni}_{50,6}$, having a value of $0.87 \mathrm{eV}$, which coincides with the value $\mathrm{E}_{\mathrm{m}}$ obtained by PAS method. A higher value $\mathrm{E}_{\mathrm{m}}$ could be associated with the different chemical composition of samples. There is only one theoretical estimate [25] for $\mathrm{E}_{\mathrm{m}}$ in TiNi - $1.2 \mathrm{eV}$.

\section{Point defects and diffusion mechanism in $\mathrm{B} 2$ phase of $\mathrm{TiNi}$ and other B2 compounds}

It is considered that the diffusion mechanism in B2 compounds should be different from that in pure bodycentered cubic (BCC) metals, as nearest neighbour jumps of atoms destroys long-range order in the arrangement of atoms. Different diffusion mechanisms are proposed following which diffusion in B2 structure is possible (6jump cycle, triple defect mechanism and others) [30]. The diffusion mechanism in TiNi has been investigated by the radio-tracer method [2, 31, 32]. This method showed that $\mathrm{Ti}$ atoms diffused to one-two order slower than $\mathrm{Ni}$ atoms. It was proposed [2] that as $\mathrm{Ni}$ atoms are smaller than $\mathrm{Ti}$ atoms they could diffuse by interstitial diffusion mechanism, however, this is impossible [32]. Another assumption also $[2,31]$ has been excluded, i.e. possibility "anomaly" of high $\mathrm{Ni}$ atomic mobiltiy is associated with the existing structural vacancies in TiNi, which experimentally and theoretically proved their nonexistence in TiNi.

Applying values $E_{m}$ and $E_{v}$ the self-diffusion energy in TiNi can be calculated. If the diffusion mechanism could be considered as vacancy mediated, then we have: $\mathrm{E}_{\mathrm{D}}=\mathrm{E}_{\mathrm{v}}$ $+\mathrm{E}_{\mathrm{m}}=0.78 \mathrm{eV}+0.7 \mathrm{eV}=1.48 \mathrm{eV}$, which is practically coincides with $\mathrm{E}_{\mathrm{D}}$ determined by radio-tracer method $[1,2,31]$. According to diffusion data the most probable atom jump is the next-nearest-neighbour jump [32]. Experiments in quasielastic neutron scattering [33] showed that elementary diffusion in B2 compounds occurs via nearest neighbour jumps of atoms. However, atom lifetime in this state is rather short and ultimately, the diffusion is the next-nearest-neighbour jumps. The low-energy phonons determinate the direction along which the interatomic interaction are weakening. The correlation between "soft" phonon modes and $\mathrm{E}_{\mathrm{D}}$ can be observed in BCC metals [34]. In B2 compounds this photon mode is direction $<110>$. If diffusion mechanism is vacancy mediated, then phonon frequency on the Birillouin zone boundary in this direction should be also correlated to the value $\mathrm{E}_{\mathrm{m}}$ (figure 3 ).

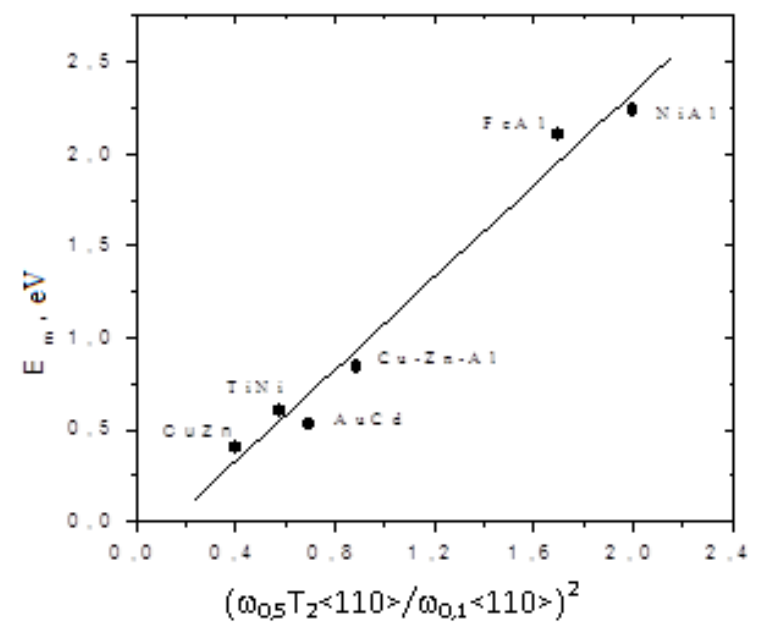

Figure 3. Dependency of activation energy for vacancy migration versus normalized phonon frequency on the Birillouin zone boundary in $\langle 110\rangle$ direction for an ordered alloys and compounds with B2 structure.

It should be noted that phonon frequency $\mathrm{T}_{2} 1 / 2<110>$ in investigated alloys AuCd, CuZn, TiNi in B2-phase is low [35-37], which results in a relatively low value $E_{D}$ and $E_{m}$. The phonon frequency for compounds FeAl and $\mathrm{NiAl}[38,39]$ are significantly higher than in abovementioned alloys which reflect relatively high value $E_{D}$ and $E_{m}$ within these alloy systems (figure 3). Thus, described investigation could be evidence of the facts discussed in [3-5] concerning the predominance of vacancy diffusion mechanism in B2 compounds at low temperatures which found its support in $\mathrm{TiNi}$ data described above.

\section{Point defects in TiNi within B2 phase homogeneity}

The deviation from equiatomic composition lead to a decrease in MT B2 $\rightarrow$ B19 $9^{\prime}\left(\mathrm{M}_{\mathrm{s}}\right)$ in Ni- rich alloys and to the changing sequence of $\mathrm{MT}$ from $\mathrm{B} 2 \rightarrow \mathrm{B} 19^{\prime}$ to $\mathrm{B} 2 \rightarrow \mathrm{R} \rightarrow \mathrm{B} 19^{\prime}$ [40]. In the early publication of Wasilevski [41] it was assumed that the high temperature $M_{s}$ in TiNi alloys, enriched by $\mathrm{Ti}$ atoms, is a result formation of the structural vacancies in these alloys (vacancies with zero formation energy). According to his hypothesis vacancy decreases B2 phase stability in TiNi, while substitution atoms (antisite atoms) increase this stability. This 
determines the concentration dependency $\mathrm{M}_{\mathrm{s}}$ within TiNi homogeneity [41].

Based on the comparison investigation of the lattice parameter concentration dependence and pycnometric density in TiNi alloys close to equiatomic composition, quenched in water at $1073 \mathrm{~K}$ [42] and correlation to predictive models of this dependence, the point defects in the region of B2-phase homogeneity was investigated. An analysis is made of the possibility of the formation of vacancies, interstitial atoms, triple defects, and substitutional (antisite) defects in the alloys. It is concluded that only antisite point defects are formed: nickel atoms which are "excess" atoms relative to those found at the lattice site in the B2 structure are located in the titanium sublattice; whereas, structural vacancies in TiNi-based binary alloys should not exist.

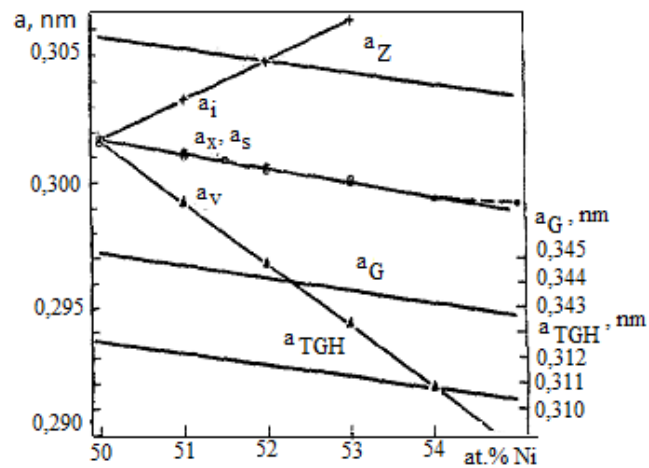

Figure 4. Change in the lattice parameter of the B2 -phase of

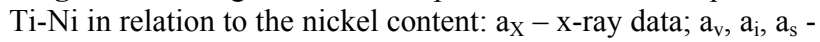
calculation from density with the presumed formation of vacancies, interstitial atoms, and antistructural atoms of nickel, respectively. Calculation in accordance with Zen's law $\left(\mathrm{a}_{\mathrm{z}}\right)$ and atomic radii of Goldschmidt $\left(\mathrm{a}_{\mathrm{G}}\right)$ and Tatum, Gschneidner, and Huber $\left(\mathrm{a}_{\mathrm{TGH}}\right)$ [4].

The PAS method also proves the absence of the structural vacancies in the region of TiNi B2-phase homogeneity [17] and the possible presence only an antisite [10]. Theoretical investigation [26] also verifies this fact. Effective formation energy of antisite atoms (AS) in B2 phase of TiNi is significantly lower than the vacancy formation energy and is $0.65 \mathrm{eV}$ for $\mathrm{Ni} \mathrm{AS}$ and $0.64 \mathrm{eV}$ for $\mathrm{Ti} \mathrm{AS}$. In this case, in Ni-enriched alloys basic point defect is $\mathrm{Ni}$ AS on Ti atom sublattice, while in $\mathrm{Ti}$ enriched alloys - Ti AS on the $\mathrm{Ni}$ atom sublattice. According to calculations, the nearest-neibghboring $\mathrm{Ni}$ AS are attractive to each other, whereas the second nearest -neighboring $\mathrm{Ni}$ repel each other and $\mathrm{Ti} \mathrm{AS}$ mutually attract; and this can be explained the asymmetry of the homogeneity region in respect to equiatomic composition [26].

\section{The role of point defects in martensitic transformation}

Experimentally shown that in $\mathrm{Au}_{47,5} \mathrm{Cd}_{52,5}$ alloy there are excess vacancies, quenched from region of high temperatures, which act as a trigger for MT $\beta_{1} \rightarrow \xi_{2}$ [43]. This MT does not occur under the condition if the heating temperature of a sample is higher than $385 \mathrm{~K}$, and excess vacancies migrate to sinks [44]. This is associated with the fact that $\mathrm{E}_{\mathrm{v}}$ in these alloys is low providing high concentration equilibrium vacancies about $10^{-2}-10^{-3}$. TiNi-based alloys with such high vacancy concentration cannot be formed by quenching from region of high temperatures. In this case, there is no effect on sequence the MT, however, they can effect diffusion controlled transformations, for example, low-temperature aging [45].

In Ti-based B2 compounds antisite atoms could significantly affect pre-transformation processes and MT. Recently, based on the molecular dynamics method, a model investigation was conducted showing the effect of vacancy with concentration from $0.1 \%$ to $3 \%$ and antisite atoms with concentration of $0.1 \%$ to $1 \%$ on MT temperature in TiNi [46]. The modeling showed that the introduction of vacancy results in the MT temperatures decreases according to linear law. An antisite atom also decreases MT temperature according to linear law, more significantly than in the case of vacancies. At the same time, it was revealed that MT hysteresis width decreases at AS concentration increase. This is generally consistent with the existing experiments. Electron irradiation, when vacancies formed, weakly effects MT temperature [47, 48], whereas, the rate of decreasing temperature $M_{s}$ is very high. Calculation of changing latent heats of transformation B2 $\rightarrow$ B19' in virtual crystal approximation and density functional theory in supercell approach in binary TiNi alloys in the region of B2 homogeneity phase were conducted in Ref. [49]. Based on these calculations $\mathrm{M}_{\mathrm{s}}$ decrease is affected not by the change of alloy electron structure, but by the disturbing effect of point defects - antisite atoms. It was proved that the introduction of $\mathrm{Ni}$ AS produces strong relaxation of neighboring atoms advancing B2 structure phase to martensitic phase. At the same time, the increase of $\mathrm{Ni}$ AS results in the decrease of latent heats of transformation B2 $\rightarrow$ B19', which, in its turn, decreases $\mathrm{M}_{\mathrm{s}}$. Point defects determine the behavior of structural changes in the pre-transformation region of temperature, preceding $\mathrm{B} 2 \rightarrow \mathrm{R}$ MT [50]. However, the role of point defects in the process of martensitic phase formation is still controversial [51]. There is an alternative view in determining the role of nesting features in the Fermi surface of $\mathrm{TiNi}$ in the process of martensitic phase formation [52].

\section{Vacancy defects in TiNi after severe plastic deformation (SPD)}

The vacancies, formed during severe plastic deformation (SPD) could affect the properties and structure-phase transformations in TiNi. On the one hand, they can accelerates the mass transfer processes and to promote the formation of ultrafine-grained structure during SPD (the formation or decomposition supersaturated solid solution, dissolution phases [53], creation of new highangle grain boundaries [54]). On the other hand, vacancies under conditions of high concentrations and low mobility could form agglomerates and to promote the formation of nanoporosity. Based on recent publications, the development of nanoporosity, occurring in Al-, Cu- 
based alloys after equal-channel angular pressing (ECAP), causes the decrease in the long-time durability [55]. Most investigations on the formation deformation vacancies at SPD were conducted predominantly on pure metals [56-58], which was under conditions of ambient temperature when vacancy mobility is comparably low.

Based on the PAS method positron lifetime spectra in alloy samples $\mathrm{Ti}_{50.0} \mathrm{Ni}_{47.3} \mathrm{Fe}_{2.7}$ after ECAP at $723 \mathrm{~K}$ were measured. The microstructure changes after ECAP have been described in $[59,60]$, while positron measurement conditions of positron lifetime spectra and spectrometry have been described in [58]. The investigated samples after ECAP showed that the average positron lifetime significantly increases immediately after the first pressing pass and remains practically unchangeable during the increasing number of ECAP pressing pass. This behavior can be observed in micro-hardness (figure 5).

If the micro-hardness increase is associated with the decrease of grain size during ECAP, then the average positron lifetime increase indicates the rising defect concentrations in the crystal lattice under conditions of deformation accumulations. To determine the defect types after ECAP necessary condition is decomposition of positron lifetime spectra into components. This decomposition revealed that the basic defects trapped by positrons are dislocations and vacancies. Estimates made as in Ref. [61] showed that after ECAP vacancy concentrations in TiNi based alloy are $\sim 10^{-4}-10^{-5}$, which has significantly higher order than thermodynamic equilibrium concentration. Besides, positron lifetime in vacancies equal $\sim 200 \mathrm{ps}$, which correspond to the vacancies formed on the Ti sublattice in B2 structure of TiNi, based on the theoretical calculations [62].

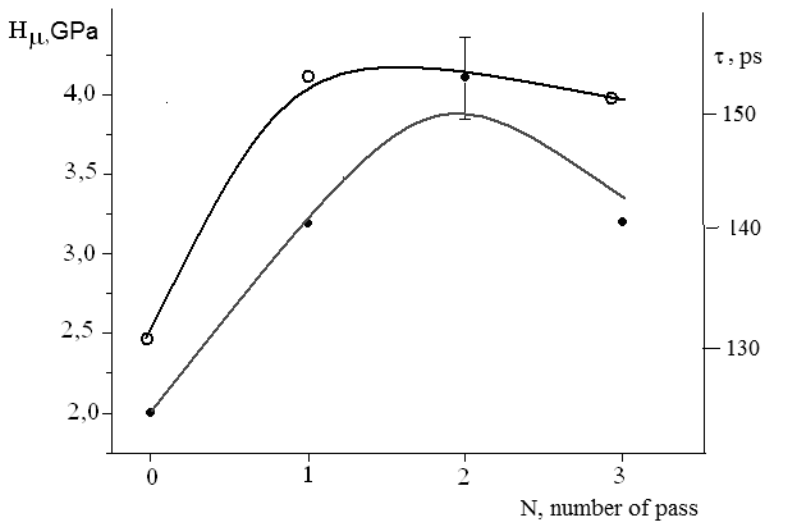

Figure 5. Dependence of average positron lifetime and microhardness versus number of ECAP pressing pass for alloy $\mathrm{Ti}_{50.0} \mathrm{Ni}_{47.3} \mathrm{Fe}_{2.7}$

\section{Acknowledgments}

The present work is financially supported by RFBR (project № 15-08-99489) and the Program of Fundamental Researches of the State Academies of Science for 2013-2020 (project № III.23.2.2).

\section{References}

1. G.F. Bastin, G.D. Rieck, Met. Trans. 5, 1827 (1974)

2. G. Erdelyi, Z. Erdelyi, D.L Beke., J. Bernardini, C. Lexcellent, Phys. Rev. B 62, 11284 (2000) .

3. G.P. Tiwari, R.S. Mehrotra, Metall. Mater. Trans. A.,43, 3654 (2012)

4. I.V. Belova, G.E. Murch, Metall. Mater. Trans. A. 44, 4417 (2013)

5. G. P. Tiwari, R. S. Mehrotra, Metall. Mater. Trans.A. 44, 4422 (2013)

6. I I. Novikov, Rev. int. hantes temper. refract. 16, 413 (1979)

7. J.V. Paemel, R. Cottam, L. Delaey Z. Metallkde. 66, $453(1975)$

8. Y. Yamada, Met. Trans. A 19, 777 (1988)

9.A.I. Potekaev, A.A. Klopotov, V.V. Kulagina, V.E. Gunter, Steel in translation 40, 881 (2011).

10. A.I. Lotkov and A.A. Baturin, Positron Spectroscopy of B2-Titanium Compounds: Electronic Structure, Point Defects, and Martensitic Transformations (NauchnoTekhnicheskaya Literatura, Tomsk, 2004) (In Russian)

11. H.-E. Schaefer, R. Würschum, M. Šob e.a., Phys. Rev. 41, 11869 (1990)

12. U. Brossmann, R. Würschum, K. Badura, H.-E. Schaefer, Phys. Rev.B. 49, 6457 (1994)

13. E.A. Kummerle, K. Badura, B. Sepiol e.a., Phys. Rev. B. 52, R6947 (1995)

14. K. Badura-Gergen, H.-E. Schaefer, Phys. Rev. B. 56, 3032 (1997)

15. R. Würschum, C. Grupp, H.-E. Schaefer, Phys. Rev. Let. 75, 97 (1995)

16. A.A. Baturin, A.I. Lotkov Phys. Met. Metallogr., 76, 24 (1993)

17. K. Kuribayashi, S. Tanigawa, S. Nanao and M. Doyama, Sol. State Comm., 12, 1179 (1973)

18. J. Katsuyama, T. Kobayashi, P. Chalermkarnnon e.a., Mat. Trans. JIM., 47, 1489 (2002)

19. R. Grone, J. Hascik, V. Slugen e.a., Nucl. Instrum. Methods Phys. Res. Sect. B 129, 284 (1997)

20. J. Winter, H. Matter, W. Triftshauser, Pros. 5th Int. Conf. Positron Annihilation. (Japan, 111, 1979)

21. S.T. Chabik, B. Rosenfeld, Appl. Phys. 25, 143 (1981)

22. W. Triftshauser, Phys. Rev. B. 12, 4634 (1975)

23. G.L Zhao, T.C. Leung, B.N. Harmon, M. Keil, M. Mullner, W. Weber, Phys. Rev. B. 40, 7999 (1989)

24. M.H. Weber, T. Ablekim, K.G. Lynn, J. Physics: Conference Series 505 (2014) 012006 doi:10.1088/1742$6596 / 505 / 1 / 012006$

25. T. Russell, M. Lutton, J. Sabochick, N. Q. Lam, MRS Proceedings, (1990). 209, 207 doi:10.1557

26. J. M. Lu, Q. M. Hu,L. Wang e.a., Phys. Rev. B 75, 094108 (2007)

27. R. Würschum, K. Badura-Gergen, K. Kümmerle, C. Grupp, H.-E. Schaefer, Phys. Rev. B 54, 849 (1996)

28. A.A. Baturin, A.I. Lotkov, Izvestiya Vysshikh Uchebnykh Zavedenij. Fizika 26, 115 (1983), (In Russian) 
29. R. Kołodziej, J. Sołtys, Mater. Sci. Eng. A 151, L5 (1992)

30. H. Mehrer, Recent Progress in Diffusion, Thermodynamics and Kinetics in Intermetallic Compounds (Diffusion Foundations 2, 1, 2014)

31. J. Bernardini, C. Lexcellent, L. Daróczi, D. L. Beke, Phil. Mag. 83, 329 (2003)

32. S.V. Divinski, I. Stloukal, L. Kral, Chr. Herzig, Def. Diff. Forum 289-292, 377 (2009)

33. M. Kaisermayr J. Combet, H. Ipser, H. Schicketanz, B. Sepiol, G. Vogl, Phys. Rev. B. 61, 12038 (2000)

34. W. Petry, Journal de physique IV. C2, 5, 15 (1995)

35. T. Ohba, S.M. Shapiro, S. Aoki, K. Otsuka, Jpn. J. Appl. Phys. 33, L1631(1994)

36. G. Gilat, G. Dolling, Phys. Rev. A 138, 1053 (1965)

37. G. Herget, M. Mullner, G. Eckold, H. Jex, Proc. third conf. on phonon phys. and sixth int. conf in condens. Matter (Heiderlberg, 55, 1989)

38. S. M. Shapiro, B. X. Yang, G. Shirane e.a., Phys. Rev. Lett. 62, 1298 (1989)

39. B. Meyer, V. Schott, M. Fähnle, Phys.Rev. B. 52, R14673 (1998)

40. Y. Kawamura, A. Gyobu, T. Saburi, M. Asai, Mater. Sci. Forum 327-328, 303 (1999)

41. R.J. Wasilewski, S.R. Butler, J.E. Hanlon, D. Worden, Metall. Trans. 2, 229 (1971)

42. V.N. Grishkov, A. I. Lotkov, Sov. Phys. Journal. 30, 941 (1987)

43. T. Suzuri, M. Takagi, A. Nagasawa, N. Nakanishi, J. Mater Sci. 16, 3013 (1981)

44. N.Nakanishi, M. Takano, H. Morimoto e.a., J de Physique. 43, 721 (1982)

45. S. Kustov, B. Mas, D. Salas e.a., Scripta Mater. 103, $10(2015)$

46. A.M. Techrani, H. Shahrokhshani, N. Parvin, J. Brgoch, arXiv: 1504.08242v [cond-mat.mtrl-sci] 2015.
47. X.T Zu., L.M. Wang, Appl. Phys. Lett. 80, 31 (2002) 48. Zu X., Lin L.B., J. Alloys Compounds. 351, 87 (2003)

49. J. Frenzel, A. Wieczorek, I. Opahle, B. Maßß, R. Drautz, G. Eggeler, Acta Mater. 90, 213 (2015)

50. Z. Zhang, Yu. Wang, D. Wang Y. Zhou, K. Otsuka, X. Ren, Phys. Rev. B. 224102 (2010)

51. J. Liu, X. Jin, Phys. Status Solidi B 251, 2055 (2014)

52. A. I. Lotkov, A. A. Baturin, Phys. Mesomech. 14, 261 (2011)

53. A.G. Kesarev, V.V. Kondrat'ev, Phys. Met. Metallography 102, 10 (2006)

54. V. M. Farber, Metal Science Heat Treat. 44, 317 (2002)

55. V.I. Betekhtin, A.G. Kadomtsev, P. Kral e.a., Mater. Science Forum 567-568, 93 (2008)

56. J. Čížek, O. Melikhova, Z. Barnovská, I. Procházka, R. K. Islamgaliev, J. Physics: Conf. Series 443, 012008 (2013)

57. M.J. Zehetbauer, G.Steiner, G. Schafler, A. Korznikov, E. Korznikova, Mater. Science Forum 503504, 57 (2006)

58. P.V. Kuznetsov, Yu. P. Mironov, A. I. Tolmachev e.a., Phys. Solid State, 57, 219 (2015)

59. V.N. Grishkov, A.I. Lotkov, A.A. Baturin, V. N. Timkin, V. I. Kopylov, Izvestiya. Ferrous Metallurgy, 12, 50 (2014) (In Russian)

60. V.G. Pushin, R.Z. Valiev, U.T. Zhu e. a., Mat. Trans. JIM 47, 694 (2001)

61. R. Kužel, M. Janeč, Z. Mate e.a., Metall. Mater. Trans. A. 41, 1174 (2010)

62. M. Mizuno, H. Araki, Y. Shirai, Adv. Quan. Chem. 42, 109 (2003) 